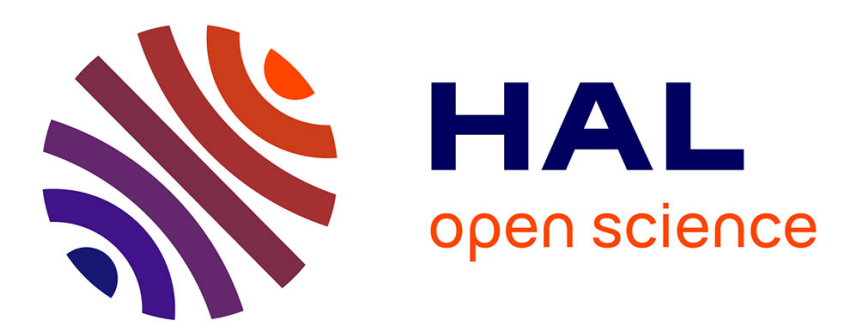

\title{
Low Temperature Deposition of Highly Cyclable Porous Prussian Blue Cathode for Lithium-Ion Microbattery
} Sai Gourang Patnaik, David Pech

\section{To cite this version:}

Sai Gourang Patnaik, David Pech. Low Temperature Deposition of Highly Cyclable Porous Prussian Blue Cathode for Lithium-Ion Microbattery. Small, 2021, 17 (25), pp.2101615. 10.1002/smll.202101615 . hal-03272953

\section{HAL Id: hal-03272953 \\ https://hal.laas.fr/hal-03272953}

Submitted on 28 Jun 2021

HAL is a multi-disciplinary open access archive for the deposit and dissemination of scientific research documents, whether they are published or not. The documents may come from teaching and research institutions in France or abroad, or from public or private research centers.
L'archive ouverte pluridisciplinaire HAL, est destinée au dépôt et à la diffusion de documents scientifiques de niveau recherche, publiés ou non, émanant des établissements d'enseignement et de recherche français ou étrangers, des laboratoires publics ou privés. 


\title{
Low Temperature Deposition of Highly Cyclable Porous Prussian Blue Cathode for Lithium-Ion Microbattery
}

Sai Gourang Patnaik*, and David Pech*

Dr. S. G. Patnaik, Dr. D. Pech

LAAS-CNRS, Université de Toulouse, CNRS, 7 avenue du colonel Roche, 31400 Toulouse, France

E-mail: patnaiks@hu-berlin.de, dpech@laas.fr

Keywords: microporous materials, microbattery, electrodeposition, low temperature, Prussian blue

\begin{abstract}
Small dimension Li-ion microbatteries are of great interest for embedded microsystems and on-chip electronics. However, the deposition of fully crystallized cathode thin film generally requires high temperature synthesis or annealing, incompatible with microfabrication processes of integrated Si devices. In this work, we report a low temperature deposition process of a porous Prussian blue-based cathode on Si wafers. The active material is electrodeposited under aqueous conditions using a pulsed deposition protocol on a porous dendritic metallic current collector that ensures good electronic conductivity of the composite. The high voltage cathodes exhibit a huge areal capacity of $\sim 650 \mu \mathrm{Ah} \mathrm{cm}^{-2}$ and are able to withstand more than 2000 cycles at $0.25 \mathrm{~mA} \mathrm{~cm}{ }^{-2}$ rate. The application of these electrode composites with porous $\mathrm{Sn}$ based alloying anodes is also demonstrated for the first time in full cell configuration, with high areal energy of $3.1 \mathrm{~J} \mathrm{~cm}^{-2}$ and more than $95 \%$ reversible capacity. This outstanding performance can be attributed to uniform deposition of Prussian blue materials on conductive matrix, which maintains electronic conductivity while simultaneously providing mechanical integrity to the electrode. This finding opens new horizons in the monolithic integration of energy storage components compatible with the semiconductor industry for selfpowered microsystems.
\end{abstract}




\section{Introduction}

Miniaturized energy storage solutions are key to powering the modern era of connected devices, which is at the heart of "Internet of things" (IoT) concept. Compared to the rapid advances in microelectronics, there has been relatively stunted growth in development of equivalent energy microstorage. Consequently, a vast majority of current microelectronic systems utilize off the chip energy solutions, with ohmic losses, external connections, extra surface area etc. Indeed, the space constraint in microsystems for the realization of integrated microbatteries makes the task daunting, especially when the synthetic methodology of active material involves utilization of high temperature/pressure conditions. In this pursuit, one of the major constraints for microelectronics is that of the demand of decent energy/power density $(\sim 10 \mu \mathrm{W}, \sim 1 \mathrm{~J}$ for one day of continuous operation ${ }^{[1]}$ from limited footprint area with good cyclability. One widely accepted game changer is that of $3 \mathrm{D}$ or porous electrode design with high surface-to-volume ratio, to have interfacial exchanges over an extended surface with better electrolyte accessibility, short ionic diffusion paths and mass transport kinetics, thereby decoupling the inverse energy/power relationship. ${ }^{[2-6]}$ Various advanced coating techniques like chemical vapor deposition (CVD), ${ }^{[7,8]}$ atomic layer deposition (ALD), ${ }^{[9,10]}$ molecular layer deposition (MLD), ${ }^{[11]}$ sputtering, ${ }^{[12,13]}$ etc. have been used for conformal coating of active materials on porous structures. However, such techniques need expensive instrumentation, high vacuum and high temperature conditions, exotic organometallic precursors as starting reagents etc. ${ }^{[14,15]}$ This limits the spectrum of material engineering that can be performed on Si wafers or other low temperature polymer substrates for on-chip energy storage systems. This is especially true for cathode materials, which need high temperature annealing treatments $\left(\sim 300-800^{\circ} \mathrm{C}\right)$ for better crystallinity and electrochemical performance, even if performed by state-of-the-art ALD, sputtering techniques or from conventional slurry coating. ${ }^{[13,16,17]}$ 
While traditional metal oxides, phosphates or fluoride-based cathodes require high temperature treatment, prussian blue analogue $(\mathrm{PBA})\left(\mathrm{A}_{x} \mathrm{M}\left[\mathrm{Fe}(\mathrm{CN})_{6}\right]_{y} \cdot \mathrm{zH}_{2} \mathrm{O}\right.$, where $\mathrm{A}$ and $\mathrm{M}$ are alkali and transition metal ions, respectively) based cathode materials are synthesized under relatively mild conditions in aqueous medium from easily available low cost precursors. ${ }^{[18]}$ They have an open framework robust structure and the Fe center exhibits a redox potential of 3.4 $\mathrm{V}$ [vs. $\left.\mathrm{Li} / \mathrm{Li}^{+}\right],{ }^{[19]}$ which is ideal for utilization as cathodes for $\mathrm{Li}$-ion batteries. $\mathrm{A}_{\mathrm{x}} \mathrm{Fe}\left[\mathrm{Fe}(\mathrm{CN})_{6}\right]_{\mathrm{y}} \cdot \mathrm{zH}_{2} \mathrm{O}(\mathrm{Fe}-\mathrm{PBA})$ in particular has high theoretical capacity towards $\mathrm{Li}$ ion redox (> $150 \mathrm{mAh} \mathrm{g}^{-1}$ ) owing to two redox active centers. Such properties are definitely elusive from the point of view of application in microbatteries, which is the focus of the current study. However, PBA analogues which have been utilized as thin film cathodes in the past for Li-ion batteries have low reversible capacity and cycling stability, owing to a mix of several factors including low intrinsic electronic conductivity, presence of crystal water etc. Hence, in the current study, we developed a microelectrode set up consisting of homogeneous dispersion of Fe-PBA type cathodes inside a 3D nanoporous current collector framework using facile onestep pulsed electrodeposition technique under ambient conditions. The composite electrode, without any binder/carbon additive (thus no additional resistive components), exhibits excellent cycling stability - up to 2000 cycles - and rate performance towards reversible two $\mathrm{Li}^{+}$insertion reactions into the Fe-PBA framework. These outstanding properties can be partly attributed to the strategically optimized conductive porous network as well as low water content of the $\mathrm{Fe}$ PBA material obtained through optimized and industrially scalable electrodeposition procedure. We further demonstrate the full cell performance of the resulting Fe-PBA electrode composite with a porous Sn based anode material in stacked configuration, thus opening up their full-scale potential for commercialization. 


\section{Results and Discussion}

\subsection{Conformal Deposition of PBA on Highly Porous Current Collectors}

Three-dimensional porous metallic current collectors were constructed by a facile optimized electrodeposition process on oxidized Si wafers (Figure S1). While the evolution of hydrogen gas (arising from the reduction of protons at low overpotential) is often a troublesome process accompanying electrodeposition, this feature can be exploited to template the growth of highly porous metals. This process, known as the dynamic hydrogen bubble template (DHBT) method, can be utilized to create a wide range of macroporous films ( $\mathrm{Ni}, \mathrm{Cu}, \mathrm{Au}, \mathrm{Co}, \mathrm{Ti} . .$.$) with$ nanostructured pore walls. ${ }^{[20]}$ As a proof-of-concept and owing to experimental considerations, we performed the DHBT with Au, which can be, nevertheless, replaced by a cheaper metal. The thickness, $t$, apparent porosity, $p$, and aspect ratio, $A R$, (defined as the ratio between the electrochemical active surface area and the geometrical surface area) of the porous films used in this study were $t=59 \mu \mathrm{m}, p=88.0 \%$ and $A R=900 \mathrm{~cm}^{2} / \mathrm{cm}^{2}$.

Following this, Fe-PBA $\left(\mathrm{Na}_{x} \mathrm{Fe}_{y}\left[\mathrm{Fe}(\mathrm{CN})_{6}\right] \cdot \mathrm{a} \square \cdot \mathrm{bH}_{2} \mathrm{O}\right.$, where $\square$ is $\left[\mathrm{Fe}(\mathrm{CN})_{6}\right]^{-}$vacancy) was electrochemically grown within the porous current collector matrix by a pulse potential program ( $1 \mathrm{~s}$ pulse $\mathrm{ON}$ at $-0.5 \mathrm{~V}$ vs. SCE, $5 \mathrm{~s}$ pulse $\mathrm{OFF})$. Three different pulse periods, namely 1500 s pulse ON (PBA-1.5), 3000 s pulse ON (PBA-3) and 5000 s pulse ON (PBA-5) were evaluated to analyze the effect of deposition duration of Fe-PBA on the porous substrate (the thickness of the porous substrate was maintained at 50-60 $\mu \mathrm{m}$ all through). The electrodeposition bath conditions were obtained from previously reported literature and modified accordingly. ${ }^{[21]}$ The $\mathrm{Na}^{+}$in Fe-PBA could then be substituted with $\mathrm{Li}^{+}$during galvanostatic cycling as previously reported. ${ }^{[21,22]}$ Figure $\mathrm{S} 2 \mathrm{a}$ shows the structure of electrodeposited Fe-PBA having 8 subunits for possible interaction with $\mathrm{Na}$ ions (red spheres). After electrochemical cycling in $\mathrm{Li}^{+}$containing organic electrolyte, the $\mathrm{Na}^{+}$ions can be substituted with $\mathrm{Li}^{+}$(Figure S2b) to obtain $\mathrm{Li}-\mathrm{Fe}-\mathrm{PBA}\left(\mathrm{Na}_{z} \mathrm{Li}_{x} \mathrm{Fe} y\left[\mathrm{Fe}(\mathrm{CN})_{6}\right] \cdot \mathrm{a} \square \cdot \mathrm{bH}_{2} \mathrm{O}\right)$. This 
approach is beneficial as, 1) there are no commercially available $\mathrm{Li}\left[\mathrm{Fe}(\mathrm{CN})_{6}\right]$ precursors and also 2) larger radii of hydrated $\mathrm{Li}^{+}$ion in aqueous deposition bath will not allow all cubic sites to be filled with $\mathrm{Li}^{+}$ions, resulting in a structure with high vacancies (unlike $\mathrm{Na}^{+}$ions which have relatively small hydrated radii and can easily fit in cubic sites). ${ }^{[23]}$ However, upon electrochemical lithiation in organic electrolyte, the relatively minute water content will not hinder insertion of $\mathrm{Li}^{+}$ions. Before electrochemical lithiation, the samples were dried under vacuum at $60{ }^{\circ} \mathrm{C}$ for a minimum of six hours to remove any adsorbed moisture, as presence of moisture can lead to structural instabilities, side reactions and electrochemical property change in PBA analogues ${ }^{[24-26]}$ during high voltage operation. The structure of Li-Fe-PBA is illustrated in Figure 1a, consisting of a three-dimensional network of $\mathrm{Fe}^{1}-\mathrm{C} \equiv \mathrm{N}-\mathrm{Fe}^{2}$ chains along the edges of the unit cell cube. The $\mathrm{Fe}^{1}$ and $\mathrm{Fe}^{2}$ atoms are surrounded octahedrally by $\mathrm{C}$ and $\mathrm{N}$ atoms respectively, thus different spin configurations in the two $\mathrm{Fe}$ atoms: high spin configuration of $\mathrm{Fe}^{1}\left(\mathrm{t}_{2 \mathrm{~g}}{ }^{3} \mathrm{eg}^{2}\right)(\mathrm{Fe}-\mathrm{HS})$ connected to $\mathrm{N}$ and low spin configuration of $\mathrm{Fe}^{2}\left(\mathrm{t}_{2 \mathrm{~g}}{ }^{5} \mathrm{eg}_{\mathrm{g}}{ }^{0}\right)$ in (Fe-LS) connected to $\mathrm{C}$. This leads to different redox potentials during interaction with $\mathrm{Li}^{+}$ depending on the type of Fe atom involved. ${ }^{[27]}$ Scanning electron microscope (SEM, Figure 1b) images of the vacuum dried samples of Fe-PBA show cubic structures deposited over the entire porous framework, while the energy-dispersive X-ray (EDX, Figure S3) mapping indicates a homogeneous and conformal coating of Fe-PBA over the porous current collector. The X-ray diffraction (XRD) peaks (Figure 1c) are sharp and can be indexed to a fcc structure (JCPDS: 73-0687) indicating high crystallinity. In Prussian blue analogues, water can exist either adsorbed on surface, as coordinating water in the framework, or as interstitial water. Vacuum drying can remove majority of surface adsorbed water content. Hence, minor amount of remaining adsorbed water is released at $>100^{\circ} \mathrm{C}$ and most of crystal water is released at > $200^{\circ} \mathrm{C}$. In our case, the samples have less than $5 \%$ water content as analyzed by thermogravimetric analysis (TGA) studies (Figure 1d). Since vacuum drying removes majority 
of surface adsorbed water content, the remaining water content must be interstitial/coordinated water. Figure 1e shows the infrared spectroscopy (IR) results. The strong peak at $2049 \mathrm{~cm}^{-1}$ can be attributed to cyanide $\mathrm{C} \equiv \mathrm{N}$ stretching. The peak at 1615 and at $\sim 3600 \mathrm{~cm}^{-1}$ can be ascribed to in plane deformation and $\mathrm{O}-\mathrm{H}$ stretching of crystal water molecules. The in plane and out-ofplane deformations of the Fe-C bond can be observed at 596 and $456 \mathrm{~cm}^{-1}$, respectively. All the IR peaks were also narrow and sharp, further indicating a well-defined structure. In Raman spectra (Figure 1f), wavenumber peaks at 2090 and $2120 \mathrm{~cm}^{-1}$ can be associated to $\mathrm{CN}^{-}$group attached to $\mathrm{Fe}^{2+}$ whereas peak at $2150 \mathrm{~cm}^{-1}$ can be associated with $\mathrm{CN}^{-}$group attached to $\mathrm{Fe}^{3+}$ ions. ${ }^{[28]}$ The dominant peak at $2150 \mathrm{~cm}^{-1}$ indicate that the majority of $\mathrm{Fe}$ atoms are in +3 state, i.e. Prussian blue and not Prussian white.

\subsection{Electrochemical Performances of Porous PBA Electrodes}

Electrochemical characterizations of the composite porous electrodes were performed against metallic lithium in cathodic half-cell set up. Figure 2a shows the cyclic voltammograms (CVs) of Li-Fe-PBA electrodes in 1.0 M LiPF6 in ethylene carbonate (EC)/diethyl carbonate (DEC) (1:1) and 2 vol\% fluoroethylene carbonate (FEC) mixture between 2.0-4.3 V. The CV profiles exhibited two sets of reversible redox peaks (suggesting two step reversible insertion of $\mathrm{Li}^{+}$) at 3.1 / $2.8 \mathrm{~V}$ and 3.8 / 3.4 V that can be associated with redox interactions of $\mathrm{Li}^{+}$with $\mathrm{Fe}-\mathrm{HS}$ and Fe-LS respectively, as known from past studies. ${ }^{[27,29]}$ More importantly, CVs of these electrodes had almost equal current intensity from both the redox centers. This is contrary to previous reports on PBA based electrodes for $\mathrm{Li}$ ion batteries, where in most of the cases, the contributions from Fe-LS (high potential redox) is always much lower than Fe-HS (low potential redox). ${ }^{[30,31]}$ It is important to increase the contributions from both the redox centers to maximize the energy density. In addition, it is also known that interaction of active ion with the N-coordinated Fe-HS (low potential redox) results in change in lattice parameters to some 
extent while interaction with the C-coordinated Fe-LS (high potential redox) does not affect the lattice parameters much. ${ }^{[32]}$ Hence, equal contributions from the C-coordinated Fe-LS in our case is definitely an added benefit, which can ensure good capacity retention without structural degradation and needs further structural investigation. Galvanostatic charge discharge studies were also performed in a similar set up as that of CV studies (Figure 2b). The electrode (PBA5) exhibited reversible gravimetric capacity of $\sim 110 \mathrm{mAh} \mathrm{g}^{-1}$ (at $0.1 \mathrm{~mA} \mathrm{~cm}{ }^{-2}$ ), consistent with previous reports with the iron hexacyanoferrate based materials ${ }^{[31,33,34]}$ and a huge areal capacity of $\sim 650 \mu \mathrm{Ah} \mathrm{cm}^{-2}\left(\sim 5.41 \mu \mathrm{Ah} \mathrm{cm}^{-2} \mu \mathrm{m}^{-1}\right)$ as compared to other cathodic materials for microbattery applications. ${ }^{[17,35-42]}$ Indeed, the size and the compactness being the primary selection criteria, it is imperative to consider all reported properties normalized to the footprint area on the chip. The different porous Li-Fe-PBA electrodes show good rate stability with excellent capacity retention upon reverting to slower rates (Figure S4). Figure 2c shows the corresponding potential time profiles with $\sim 5.4$ hours for charging at $0.1 \mathrm{~mA} \mathrm{~cm}{ }^{-2}$, so $\sim 0.1 \mathrm{~mA}$ $\mathrm{cm}^{-2}=\sim \mathrm{C} / 5$ (since $\mathrm{nC}$ - rate means that the battery was charged in $\mathrm{t}=1 / \mathrm{n}$ hours for a given potential range).

\subsection{Long-Term Stability}

Figure $2 \mathrm{~d}$ shows the long-term cyclability of different porous Li-Fe-PBA electrodes at $0.25 \mathrm{~mA}$ $\mathrm{cm}^{-2}$. All cathode materials exhibited high reversibility with very limited capacity decay up to 100 cycles (see inset of Figure 2d), and impressive stability when extra-long measurements are performed for hundreds of cycles. The initial discharge capacity of porous PBA-5 electrode is extremely high $\left(\sim 500 \mu \mathrm{Ah} \mathrm{cm}^{-2}\right)$, however a slight capacity decrease is observed during long term cycling due to higher loading of active materials which exceeded the amount that the porous framework can support. In the case of porous PBA-1.5 with lower amount of active material loading, the initial discharge capacity is a little bit lower, but it exhibits a remarkable 
capacity retention of up to 2000 cycles due to uniform distribution of active materials within conductive porous metallic network. The amount of active material loading is optimum for PBA-3, with a stable discharge capacity of $\sim 250 \mu \mathrm{Ah} \mathrm{cm}^{-2}$ after extended galvanostatic chargedischarge cyclings. Unlike PBA-5 (Figure S5), the overall impedance of porous PBA-3 reduces after 100 cycles due to a rearrangement of $\mathrm{Li}-\mathrm{Fe}-\mathrm{PBA}$ particles in the porous framework during the initial cycling (Figure 2e).

The intrinsic low electronic conductivity and high defect content in Fe-PBA based materials in general result in modest cycling stability. In the current case, we address this important issue by a simple electrodeposition procedure with uniform distribution of active material within a conductive matrix, sustaining thousands of cycles without the use of any organic solvents or harsh conditions. Moreover, the simple strategy can be easily modified to cast microbattery electrodes in very narrow dimensions owing to the inherent simplicity of the technique. The electrochemical stability can be explained based on facilitated electronic conductivity, better electrolyte percolation and enhanced charge transfer kinetics. In contrast to conventional bulk 3D design, porous architectures provide large surface area and result in better electrolyte percolation, interfacial kinetics and overall enhanced performance due to better utilization of surface area (Figure S6). In addition, due to the large surface area in the latter case, the current density per unit surface area is drastically reduced, thus reducing the over potential of charge transfer. The voids in porous structure also provide for additional space to entertain volume expansion and deposition of electrolyte reduction/oxidation products formed during charge/discharge process. Moreover, due to more contact of active material with the current collector electronic conductivity within the electrode composite is also enhanced.

To verify that no severe aging related degradation happened upon charge-discharge cycles, post-mortem analysis was performed on the Li-Fe-PBA electrodes after prolonged cycling. Figure S7 shows the ex-situ XRD patterns of the PBA-3 electrode after 1000 cycles. The porous electrode maintains its face centered cubic structure even after long cycling, thus 
indicating its robustness. Figures S8 and S9 show the SEM images and EDX mapping of the electrodes after cycling (PBA-3 after 1000 cycles). The electrodes still maintain their initial structural arrangement even after such extensive cycling and can be seen dispersed along with electrolyte oxidation products. In order to compare this to Li-Fe-PBA deposited on flat substrate, we also parallelly tried to repeat similar electrodeposition protocol on flat samples (Figure S10). However, in this case, the flat substrate could hold only $300 \mathrm{~s}$ of pulse ON deposition, after which the materials started falling off in the deposition bath. The cells fabricated with flat samples showed a meagre capacity of $<20 \mu \mathrm{Ah} \mathrm{cm}^{-2}$ and very high cell impedance (almost three times higher than porous samples). The porous current collector acts therefore as a mechanically reinforced framework to endure prolonged electrochemical reactions while enabling high areal capacity (Figure 3) and low resistance.

\subsection{Full Cell Proof-of-Concept}

To assess the performance of this cathode material in a device, we created a full cell in a stack configuration integrated on a silicon wafer. One of the major challenges faced by PBA electrodes for $\mathrm{Na}$ ion batteries is that to couple them with appropriate anode materials to fabricate full cells because of unavailability of high rate anodes matching PBA cathodes. ${ }^{[43,44]}$ The same holds true for PBA based materials for Li ion batteries, with no reports of them being used in full cells apart from metallic lithium in non-aqueous electrolytes. ${ }^{34}$ In this regard, we have previously reported on long life cycle SnAu based porous anodes with excellent stability and rate capability for Li-ion microbattery anodes. ${ }^{[45]}$ Hence, for the first time, we report on non-vacuum technology based full Li-ion battery with porous $\mathrm{SnAu}$ anodes and PBA based porous cathode with stable cycling at $0.2 \mathrm{~mA} \mathrm{~cm}^{-2}$. Figure 4a shows the schematic of the allporous Li ion battery in stacked configuration. Figure $4 \mathrm{~b}$ shows the $\mathrm{CV}$ profiles of $\mathrm{SnAu}$ anode and $\mathrm{Li}-\mathrm{Fe}-\mathrm{PBA}$ cathode w.r.t $\mathrm{Li}^{+} / \mathrm{Li}$ at $0.5 \mathrm{mV} \mathrm{s}^{-1}$. The anode as well as the cathode were first prelithiated against Li foil (see Supporting Information for experimental details). This was 
followed by fabrication of full cell, which was then directly cycled at $0.2 \mathrm{~mA} \mathrm{~cm}^{-2}$. Figure $4 \mathrm{c}$ shows the cycling ability of the battery, (with discharge capacity normalized to footprint area) with more than $265 \mu \mathrm{Ah} \mathrm{cm}^{-2}$ capacity and $>95 \%$ coulomb efficiency, which corresponds to an average areal energy density of $3.1 \mathrm{~J} \mathrm{~cm}^{-2}\left(848 \mu \mathrm{Wh} \mathrm{cm}^{-2}\right.$ for a nominal voltage of $\left.\sim 3.2 \mathrm{~V}\right)$. The inset shows the potential vs. time profile of the full cells in 2.0-4.0 V range with each cycle taking $~ 2.5$ hours at a current rate of $0.2 \mathrm{~mA} \mathrm{~cm}^{-2}$. The porous $\mathrm{SnAu} / \mathrm{PBA}$ cell performances is compared in a Ragone plot (Figure 4d) with current microbattery manufacturers designing small-scale batteries dedicated to be co-packaged with other integrated circuits in a single or multi-chip module. ${ }^{[46,47]}$ Most of these ultra-small microbatteries have an areal energy around $2 \mathrm{~J} \mathrm{~cm}^{-2}$, revealing the strong potential of our PBA cathode for these microdevices. If we compare the power and energy, our micro-battery can thus provide with what is required by a microscale autonomous device (going to $\mathrm{nW}$ in stand-by mode to few $\mu \mathrm{W}$ during sensing, and to short pulses of few $\mathrm{mW}$ during data transmission). Moreover, the low temperature deposition techniques developed here are fully compatible with the existing microfabrication facilities of the microelectronic industry and will help to accelerate the development on-chip energy storage systems for the IoT.

\section{Conclusion}

In summary, Fe-PBA based cathode materials were uniformly distributed in a porous metallic current collector using an optimized pulse electrodeposition protocol at low temperature and then successfully utilized as cathode for Li-ion microbatteries with excellent cycling stability. Similar deposition efforts on flat substrate however lead to meagre results with very low material loading and large cell impedance. In addition, for the first time, a fully functional Liion microbattery with Prussian blue type cathode materials, without any vacuum coating technology is reported. These results exhibit the enormous potential of utilizing porous metallic 
current collectors for microbatteries, which can be further enhanced by utilization of solid/polymer electrolytes. Since, vacuum coating technologies are generally expensive and demand extensive infrastructural set up, the current study on all aqueous coating of electrode materials (both anodes and cathodes) are cost effective, industrially scalable and can be easily integrated with the current semiconductor industry for on chip microbatteries that can assist a plethora of energy harvesters.

\section{Supporting Information}

Supporting Information is available from the Wiley Online Library or from the author. The data that support the plots within this paper can be obtained free of charge from Zenodo https://zenodo.org

\section{Acknowledgements}

D. Pech acknowledges the support from the European Research Council (ERC, Consolidator Grant, ERC-2017-CoG, Project 771793 3D-CAP). This work was supported by LAAS-CNRS technology platform, a member of Renatech network.

\section{References}

[1] J. Ni, A. Dai, Y. Yuan, L. Li, J. Lu, Matter 2020, 2, 1366.

[2] N. A. Kyeremateng, T. Brousse, D. Pech, Nat. Nanotechnol. 2017, $12,7$.

[3] C. Lethien, J. Le Bideau, T. Brousse, Energy Environ. Sci. 2019, 12, 96.

[4] T. S. Arthur, D. J. Bates, N. Cirigliano, D. C. Johnson, P. Malati, J. M. Mosby, E.

Perre, M. T. Rawls, A. L. Prieto, B. Dunn, MRS Bull. 2011, 36, 523.

[5] H. Sun, J. Zhu, D. Baumann, L. Peng, Y. Xu, I. Shakir, Y. Huang, X. Duan, Nat. Rev. Mater. 2019, 4, 45.

[6] L. Liu, H. Zhao, Y. Lei, InfoMat 2019, 1, 74.

[7] Z. Chen, W. Ren, L. Gao, B. Liu, S. Pei, H. M. Cheng, Nat. Mater. 2011, 10, 424.

[8] W. G. Choi, S. G. Yoon, J. Power Sources 2004, 125, 236. 
[9] J. Multia, J. Heiska, A. Khayyami, M. Karppinen, ACS Appl. Mater. Interfaces 2020, $12,41557$.

[10] S. Moitzheim, J. E. Balder, R. Ritasalo, S. Ek, P. Poodt, S. Unnikrishnan, S. De Gendt, P. M. Vereecken, ACS Appl. Energy Mater. 2019, 2, 1774.

[11] D. M. Piper, J. J. Travis, M. Young, S. B. Son, S. C. Kim, K. H. Oh, S. M. George, C. Ban, S. H. Lee, Adv. Mater. 2014, 26, 1596.

[12] W. Zheng, X. Yu, Z. Guo, G. Song, F. Hu, Mater. Res. Express 2019, 6, 056410.

[13] X. Zhu, X. Jiang, X. Yao, Y. Leng, L. Wang, Q. Xue, ACS Appl. Mater. Interfaces 2019, $11,26880$.

[14] H. Lu, D. S. Wright, S. D. Pike, Chem. Commun. 2020, 56, 854.

[15] C. Chen, R. A. Eichel, P. H. L. Notten, J. Electroceramics 2017, 38, 230.

[16] J. Liu, M. N. Banis, Q. Sun, A. Lushington, R. Li, T. K. Sham, X. Sun, Adv. Mater. 2014, 26, 6472 .

[17] C. M. Julien, A. Mauger, O. M. Hussain, Materials (Basel). 2019, 12, 1.

[18] M. B. Zakaria, T. Chikyow, Coord. Chem. Rev. 2017, 352, 328.

[19] M. Okubo, D. Asakura, Y. Mizuno, J. D. Kim, T. Mizokawa, T. Kudo, I. Honma, J. Phys. Chem. Lett. 2010, 1, 2063.

[20] B. J. Plowman, L. A. Jones, S. K. Bhargava, Chem. Commun. 2015, 51, 4331.

[21] Y. Moritomo, M. Takachi, Y. Kurihara, T. Matsuda, Appl. Phys. Express 2012, 5, 041801.

[22] T. Matsuda, Y. Moritomo, Appl. Phys. Express 2011, 4, 4.

[23] Q. Yang, W. Wang, H. Li, J. Zhang, F. Kang, B. Li, Electrochim. Acta 2018, 270, 96.

[24] A. Mullaliu, G. Aquilanti, P. Conti, M. Giorgetti, S. Passerini, ChemSusChem 2020, 13,608 .

[25] B. Xie, L. Wang, J. Shu, X. Zhou, Z. Yu, H. Huo, Y. Ma, X. Cheng, G. Yin, P. Zuo, ACS Appl. Mater. Interfaces 2019, 11, 46705. 
[26] J. Wu, J. Song, K. Dai, Z. Zhuo, L. A. Wray, G. Liu, Z. X. Shen, R. Zeng, Y. Lu, W. Yang, J. Am. Chem. Soc. 2017, 139, 18358.

[27] L. Wang, J. Song, R. Qiao, L. A. Wray, M. A. Hossain, Y. De Chuang, W. Yang, Y. Lu, D. Evans, J. J. Lee, S. Vail, X. Zhao, M. Nishijima, S. Kakimoto, J. B. Goodenough, J. Am. Chem. Soc. 2015, 137, 2548.

[28] B. F. Baggio, C. Vicente, S. Pelegrini, C. C. P. Cid, I. S. Brandt, M. A. Tumelero, A. A. Pasa, Materials (Basel). 2019, 12, 15.

[29] F. Scholz, A. Dostal, Angew. Chemie Int. Ed. 1996, 34, 2685.

[30] M. H. Wong, Z. Zhang, X. Yang, X. Chen, J. Y. Ying, Chem. Commun. 2015, 51, 13674.

[31] X. Wu, M. Shao, C. Wu, J. Qian, Y. Cao, X. Ai, H. Yang, ACS Appl. Mater. Interfaces 2016, 8, 23706.

[32] D. Yang, J. Xu, X.-Z. Liao, Y.-S. He, H. Liu, Z.-F. Ma, Chem. Commun. 2014, 50, 13377.

[33] F. Paquin, J. Rivnay, A. Salleo, N. Stingelin, C. Silva, J. Mater. Chem. C 2015, 3, 10715.

[34] D. R. Shi, J. Fu, Z. Shadike, M. H. Cao, W. W. Wang, Z. W. Fu, ACS Omega 2018, 3, 7648.

[35] V. A. Sugiawati, F. Vacandio, M. Eyraud, P. Knauth, T. Djenizian, Nanoscale Res. Lett. 2016, 11, 1.

[36] V. A. Sugiawati, F. Vacandio, C. Perrin-Pellegrino, A. Galeyeva, A. P. Kurbatov, T. Djenizian, Sci. Rep. 2019, 9, 11172.

[37] Q. Xia, Q. Zhang, S. Sun, F. Hussain, C. Zhang, X. Zhu, F. Meng, K. Liu, H. Geng, J. Xu, F. Zan, P. Wang, L. Gu, H. Xia, Adv. Mater. 2021, DOI: 10.1002/adma.202003524

[38] K. Yellareswara Rao, S. Narasimham, K. Narayan, G. Mohan Rao, Mater. Today Proc. 2021, DOI: 10.1016/j.matpr.2020.03.255. 
[39] P. Sun, X. Li, J. Shao, P. V. Braun, Adv. Mater. 2021, , DOI:

10.1002/adma.202006229

[40] X. Tang, B. Lin, Y. Ge, Y. Ge, C. Lu, S. V Savilov, S. M. Aldoshin, H. Xia, Mater. Res. Bull. 2015, 69, 2.

[41] D. S. Ashby, C. S. Choi, M. A. Edwards, A. A. Talin, H. S. White, B. S. Dunn, ACS Appl. Energy Mater. 2020, 3, 8402.

[42] M. Nasreldin, R. Delattre, C. Calmes, M. Ramuz, V. A. Sugiawati, S. Maria, J. L. de B. de la Tocnaye, T. Djenizian, Energy Storage Mater. 2020, 33, 108.

[43] W. Wang, Y. Gang, Z. Hu, Z. Yan, W. Li, Y. Li, Q. F. Gu, Z. Wang, S. L. Chou, H. K. Liu, S. X. Dou, Nat. Commun. 2020, 11, 1.

[44] P. Hu, W. Peng, B. Wang, D. Xiao, U. Ahuja, J. Réthoré, K. E. Aifantis, ACS Energy Lett. 2020, 5, 100.

[45] S. G. Patnaik, A. Jadon, C. C. H. Tran, A. Estève, D. Guay, D. Pech, Sci. Rep. 2020, $10,1$.

[46] A. S. Rudyi, A. A. Mironenko, V. V. Naumov, A. M. Skundin, T. L. Kulova, I. S. Fedorov, S. V. Vasil'ev, Tech. Phys. Lett. 2020, 46, 215.

[47] P. Sun, X. Li, J. Shao, P. V. Braun, Adv. Mater. 2021, 33, 2006229. 
(a)

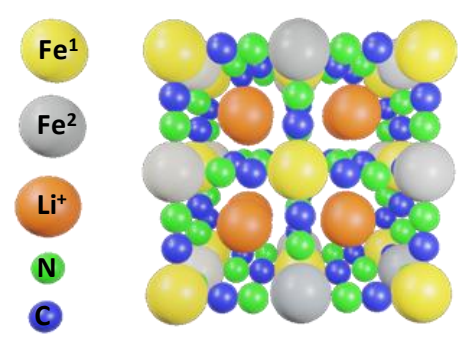

(b)

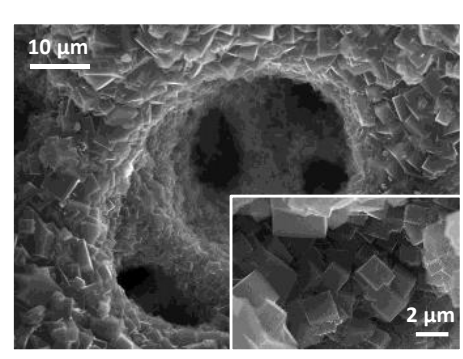

(c)

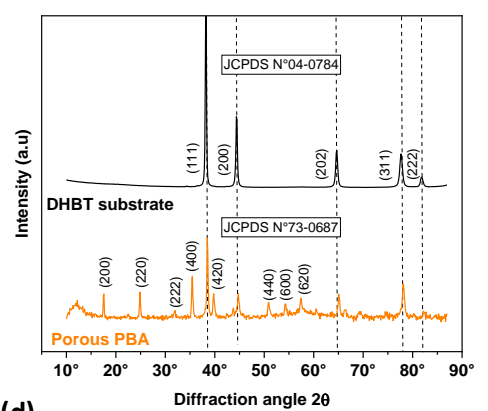

(d)

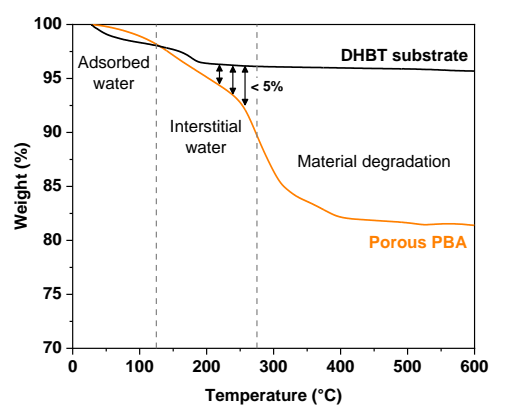

(e)

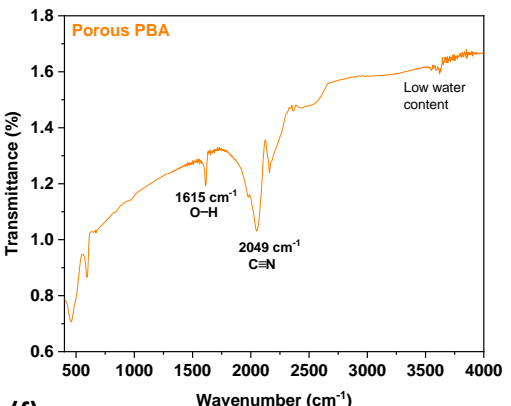

(f)

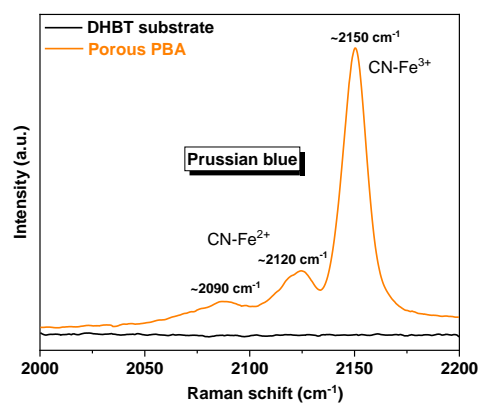

Figure 1. Physico-chemical characterizations of porous Fe-PBA electrode. a) Schematic representation of Li-Fe-PBA. b) SEM micrographs at different magnifications. c) XRD spectra of the porous current collector and as-deposited Fe-PBA (before $\mathrm{Li}^{+}$substitution). d) Thermal signature of blanc current collector and with Fe-PBA. e) IR spectra of Fe-PBA electrode after baseline correction of blank substrate. f) Raman spectra of blank current collector and with $\mathrm{Fe}$ PBA. 
(a)

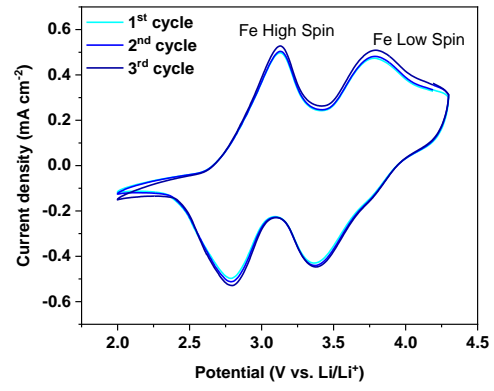

(d)

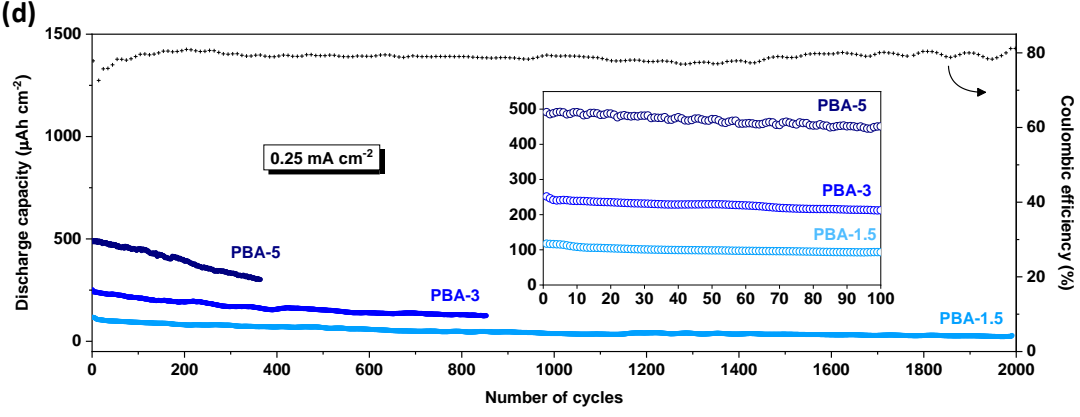

(c)
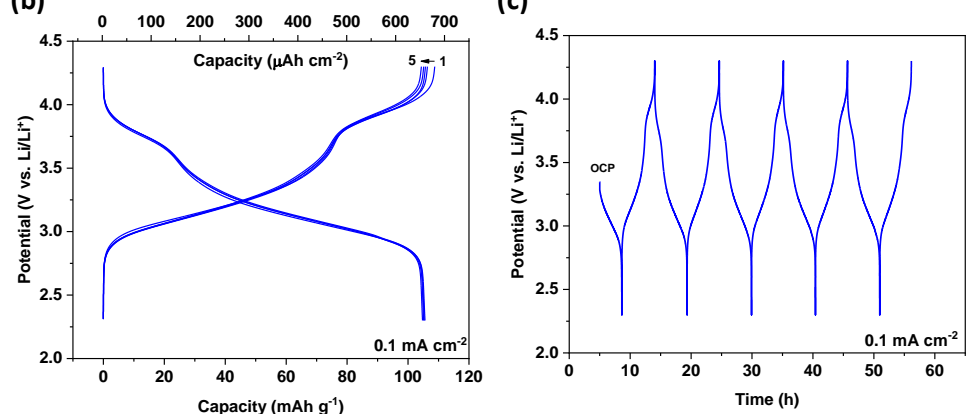

(e)

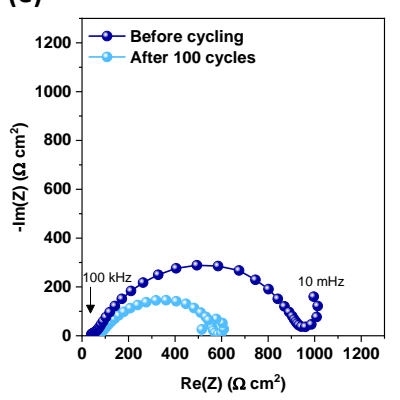

Figure 2. Electrochemical performances of porous Li-Fe-PBA electrode. a) Representative cyclic voltammogram profiles performed at $0.5 \mathrm{mV} \mathrm{s}^{-1}$ on porous PBA-3 electrode indicating high and low spin redox. b) Charge-discharge profiles $(\sim \mathrm{C} / 5)$ with gravimetric and areal capacities and c) corresponding potential-time profile. d) Long-term cycling performance of different porous PBA electrodes. e) Electrochemical impedance spectroscopy (EIS) spectra for porous PBA-3 before and after cycling. 


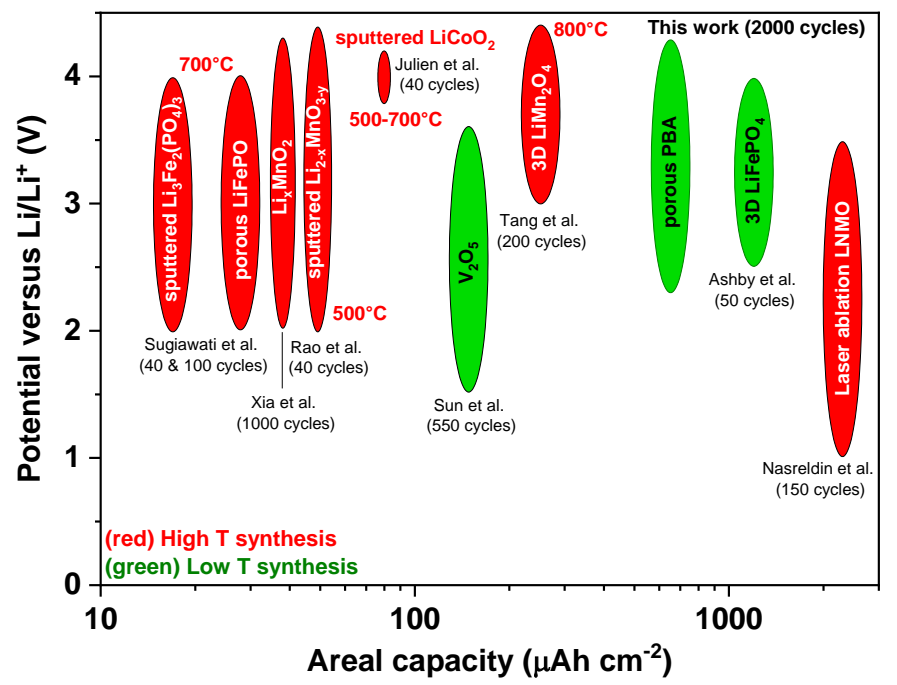

Figure 3. Areal capacity of high voltage cathodes with reported stability. ${ }^{[17,35-42]}$ In green: low temperature synthesis compatible with microfabrication process. 
(a)

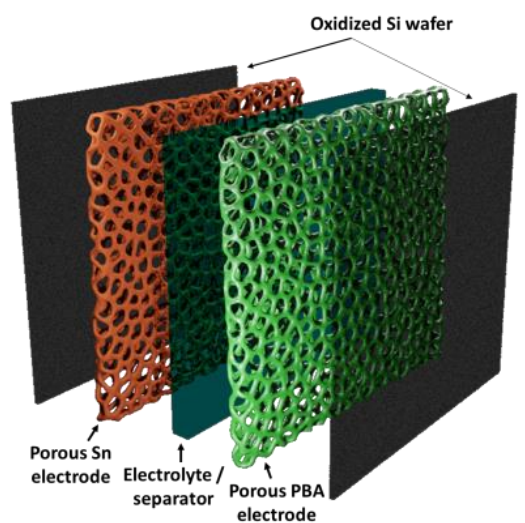

(c)

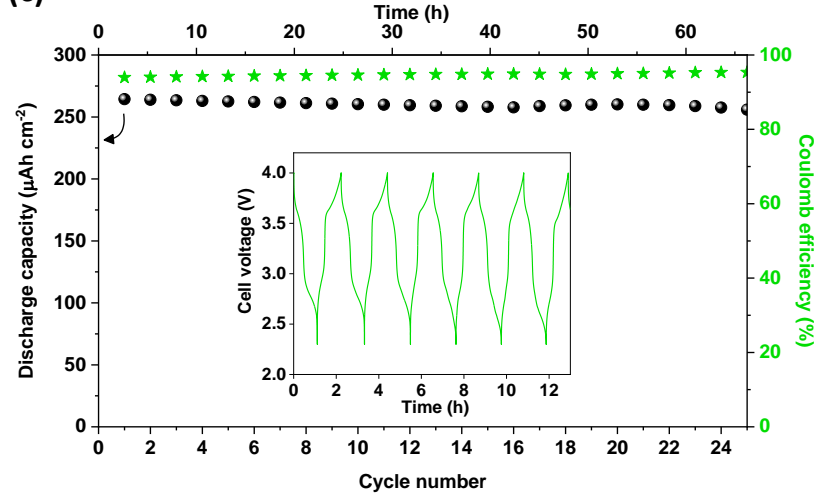

(b)

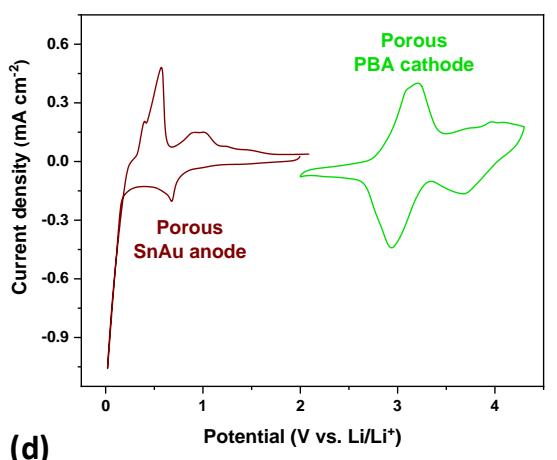

(d)

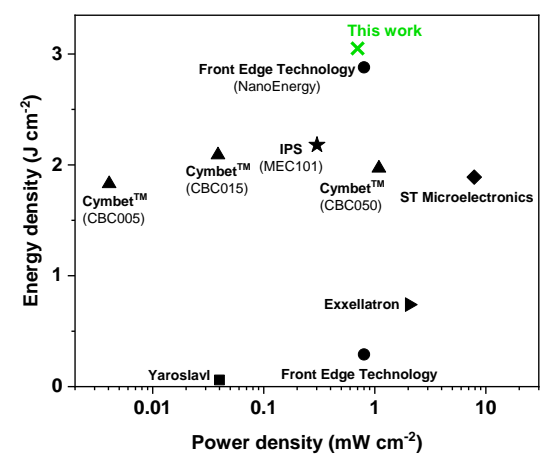

Figure 4. Full cell characterizations using a porous Li-Fe-PBA cathode. a) schematic of stacked full cell with porous $\mathrm{Sn}$-based anode and porous Li-Fe-PBA cathode. b) CV profiles at $0.5 \mathrm{mV}$ $\mathrm{s}^{-1}$ of anode and cathode w.r.t. $\mathrm{Li}^{+} / \mathrm{Li}$. c) Cycling stability of full cell and potential-time profile of the full cell at $0.2 \mathrm{~mA} \mathrm{~cm}{ }^{-2}$. d) Comparison in a Ragone plot with available commercial miniaturized microbatteries. 